Article

\title{
Sensitivity Analysis on the Rising Relation between Short-Term Rainfall and Groundwater Table Adjacent to an Artificial Recharge Lake
}

\author{
Sheng-Hsin Hsieh ${ }^{1,2}$, Li-Wei Liu ${ }^{1} \mathbb{D}$, Wen-Guey Chung ${ }^{1}$ and Yu-Min Wang ${ }^{1, * \mathbb{C}}$ \\ 1 Department of Civil Engineering, National Pingtung University of Science and Technology, \\ Pingtung 91201, Taiwan \\ 2 Department of Irrigation and Engineering, Council of Agriculture Executive Yuan, Taipei 10014, Taiwan \\ * Correspondence: wangym@mail.npust.edu.tw; Tel.: +886-931-802-656
}

Received: 15 July 2019; Accepted: 14 August 2019; Published: 16 August 2019

\begin{abstract}
This study aimed to determine the highly sensitive variables for a groundwater simulation model adjacent to an artificial recharge lake (ARL) using short-term rainfall events. The model was established using an artificial neural network (ANN) with rainfall events. Normalized rainfall, rainfall intensity, and groundwater data were selected as model variables. The coefficient of determination $\left(R^{2}\right)$ was used for model performance assessment. Finally, a sensitivity analysis (SA) was conducted to evaluate the importance of each model input. The study results indicated that the $\mathrm{R}^{2}$ of the ANN model ranged between 0.759 and 0.914 . The SA showed that the rainfall was more sensitive than rainfall intensity in the study area. Based on the SA results and relevant geological characteristics, it was observed that the rainfall of past 1-day, past 2-day, and past 3-day responded faster than the other variables to the wells near the river and the ARL. In addition, the past 2-day rainfall was highly sensitive to the groundwater table; this may be due to the fact that the well screen location was above sea level as observed in Wells 1,2, and 6. The results indicate that the groundwater table variation is response-related to the distance from the wells to the river and the ARL, and the rainfall time-lag. This SA study is helpful to researchers wishing to study related ARL efficiency issues.
\end{abstract}

Keywords: groundwater recharge; infiltration; Lin-Bien River; rainfall intensity; artificial neural network; ANN

\section{Introduction}

In the 1970s, groundwater contributed $20 \%$ of the total water usage (TWU) in Taiwan, whereas faster economic growth with industrial expansion and population increase have greatly expanded water demand in Taiwan in the 1990s, the groundwater contributing 31\% of the TWU in Taiwan [1,2]. In the 2010s, the groundwater water percentage of TWU has reached $34 \%$, achieving $64.9 \%$ in Southern Taiwan [3,4]. However, due to anthropogenic interference and climate change, the water supply is extremely unstable, groundwater withdrawals may locally exceed recharge, and undesirable conditions may develop in the aquifer and in hydraulically connected surface waters [5]. Overexploited groundwater has led to seawater intrusion, land subsidence, lowering of groundwater levels, and salinization of soil, and has reduced the well water withdrawal yields in Taiwan [6,7]. Artificial recharge has been defined, as the process of replenishing groundwater through an artificial recharge lake (ARL), to increase groundwater storage in subterranean zones [8-10]. However, the process of groundwater recharge is complex. The infiltration impact is complicated by many confounding factors such as rainfall (or applied water) intensity, micro-topography, vegetation, soil texture, and vertical and horizontal heterogeneity in soil properties [11]. Morbidelli et al. indicated that, although a variety 
of local infiltration models for vertically homogeneous soils with constant initial soil water content and over horizontal surfaces have been proposed, the estimate of infiltration at different spatial scales (i.e., from the local to watershed scales) is a complex problem as further challenges are imposed by the natural spatial variability of soil hydraulic characteristics and that of rainfall [12]. Due to the intricate mechanism of groundwater, it is hard to simulate the hydrological phenomena in a hydro model because of the applied limitation, causing the use of extremely inconvenient models [13]. The simulation accuracy could be improved, by investing much time and many resources to establish a hydro model [14]. Thus, some researchers use statistical approaches to simulate groundwater variation. These approaches can reveal the stochastic dependence among the groundwater observations and their related variables, and commonly require a relatively fewer number of parameters than a physical-based model, with limited subjective assumptions [15]. Related research studies, such as those by Daliakopoulos et al. [16], Nayak et al. [17], Sahoo and Jha [18], and Liu et al. [19]. They used multiple linear regression (MLR) and artificial neural networks (ANNs) to establish the relationship using statistical models. For example, Daliakopoulos et al. used 17 years of data to establish ANN models according to time-lag rainfall, temperature, streamflow, and groundwater table in the Messara Valley basin (Greece). The dataset was divided into three parts for the purposes of training (11 years), cross-validation (3 years), and testing (3 years). The established ANNs included a feedforward neural network (FNN), a recurrent neural network (RNN), and a radial basis function network (RBFN). The coefficient of determination $\left(\mathrm{R}^{2}\right)$ was selected to evaluate model performance. The results showed that the $\mathrm{R}^{2}$ in the FNN was between 0.592 and 0.993 , in the RNN it was between 0.609 and 0.911, and in the RBFN it was 0.744 [16]. However, in statistical model development, it is more important to select highly related inputs to acquire accurate simulation results, and to exclude data having less impact on the output of the model, to reduce the freedom degree of the model and the processing. Many scholars use a sensitivity analysis (SA) as the determination method to obtain the relative importance of model inputs. Jha and Sahoo established multilayer perception (MLP), an RNN, and an RBFN to simulate groundwater variation in 17 sites in Jiangnan, Kochi, Japan. Groundwater table differences, past rainfall, stream stage, temperature, and seasonal dummy variables were selected as inputs. In that research, data were split into four years for the model training and validation, and the remaining two years of data for the model testing. The $\mathrm{R}^{2}$ was selected for model performance evaluation. The results showed that, in 17 sites, the $\mathrm{R}^{2}$ in MLP was between 0.781 and 0.971 , in the RNN it was between 0.691 and 0.983 , and in the RBFN it was between 0.691 and 0.983 . After the ANN model was developed, an SA was conducted to identify the sensitivity of all inputs. The SA results showed that the H-4 well had the highest sensitivity for each input [20]. Ahlawat developed the relationship between precipitation and runoff using an ANN model in the Betwa catchment, India. A sensitivity analysis was conducted for model importance evaluation. The results indicated that some of the rainfall stations could be removed from the model because of the low sensitivity [21].

\section{Materials and Methods}

\subsection{Study Area}

The Lin-Bien catchment is located in Pingtung Plain, Taiwan (Figure 1, after [22]). There are three long-term record rainfall stations, namely, Taiwu-1, Xinlaiyi, and Nanhan, which were selected for rainfall data collection (Table 1). Groundwater monitoring wells included Wells 1 to 7 , which are adjacent to the catchment boundary (Table 2). The location of each rainfall station and groundwater monitoring well is illustrated in Figure 2. 


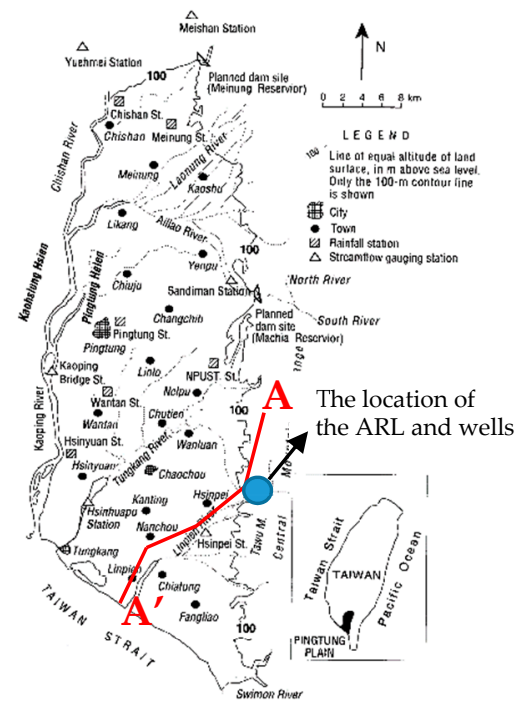

Figure 1. Location map of Pingtung Plain, after [22].

Table 1. Rainfall stations in the study catchment.

\begin{tabular}{cccccc}
\hline \multirow{2}{*}{$\begin{array}{c}\text { Rainfall Station } \\
\text { (Period) }\end{array}$} & $\begin{array}{c}\text { Annual Rainfall } \\
(\mathbf{m m})\end{array}$ & \multicolumn{2}{c}{ Coordinate } & \multicolumn{2}{c}{ Control Area } \\
\cline { 3 - 6 } & & $\mathbf{( T W D 9 7 - X )}$ & $\mathbf{( T W D 9 7 - Y )}$ & $\left.\mathbf{( k m}^{\mathbf{2}}\right)$ & $\mathbf{( \% )}$ \\
\hline Taiwu-1 (1955-2018) & 4366.2 & $217,853.20$ & $2,500,983.30$ & 50.76 & 15 \\
Xinlaiyi (1972-2018) & 3646.9 & $216,084.71$ & $2,492,152.60$ & 141.13 & 40 \\
Nanhan (1965-2018) & 2506.0 & $211,948.60$ & $2,481,928.20$ & 156.97 & 45 \\
\hline
\end{tabular}

Table 2. Information about each groundwater monitoring well in the study area.

\begin{tabular}{cccc}
\hline $\begin{array}{c}\text { Groundwater Monitoring Wells } \\
\text { (Recording Period from 2010/05 to 2015/12) }\end{array}$ & \multicolumn{2}{c}{ Coordinate } & $\begin{array}{c}\text { Well Screen } \\
\text { (Above Sea Level) }\end{array}$ \\
\cline { 2 - 3 } & (TWD97-X) & (TWD97-Y) & \\
\hline Well 1 & $211,320.61$ & $2,491,816.04$ & 24 to 33 \\
Well 2 & $211,084.75$ & $2,490,990.15$ & 14 to 23 \\
Well 3 & $210,331.36$ & $2,490,524.91$ & -17 to 5 \\
Well 4 & $210,031.63$ & $2,491,209.14$ & -18 to 6 \\
Well 5 & $209,115.70$ & $2,491,773.84$ & -17 to 5 \\
Well 6 & $209,097.66$ & $2,492,587.59$ & 13 to 25 \\
Well 7 & $210,184.92$ & $2,492,093.04$ & -5 to 7 \\
\hline
\end{tabular}

Ting et al. [23] point out that the groundwater catchment in the study area can be divided into three layers, that is, the upper layer, middle layer, and lower layer. The thickness of the upper layer, varying from 10 to $60 \mathrm{~m}$, is assumed to be an unconfined aquifer. The aquifer of the fluvial deposits in the foothills consists of coarse sand and gravel, decreasing in size to sand in a downstream direction with a thickness in excess of $220 \mathrm{~m}$. The middle layer, assumed to be semi-pervious, is a geological formation which has a very low transmissivity compared to the aquifer, with a thickness of about $20 \mathrm{~m}$ of clay and sandy clay. The lower layer is assumed to be unconfined in the upper reaches of the area and confined from the mid-fan; the storativity may thus alternate between confined and unconfined values. The aquifers are recharged directly by rainfall, river flow, and subsurface inflow from the northern upstream part of the fluvial fan. The study area is hydraulically bounded in the south by the sea (Taiwan Strait). The screens of each well were all set in the upper layer, which is mainly composed of gravel, and with slice sand, silt, and clay. The transmissivity, storativity, and maximum yield were determined as $9148 \mathrm{~m}^{2} /$ day, $6.5 \times 10^{-3}$, and $7084 \mathrm{~m}^{3} /$ day, respectively, by the Taiwan Provincial Groundwater Development Bureau [24]. The hydrogeological profile of each well in 
this study area is redrawn in Figure 3 [25], and the groundwater piezometric map of the Pingtung Plain's dry season is shown in Figure 4 [26].

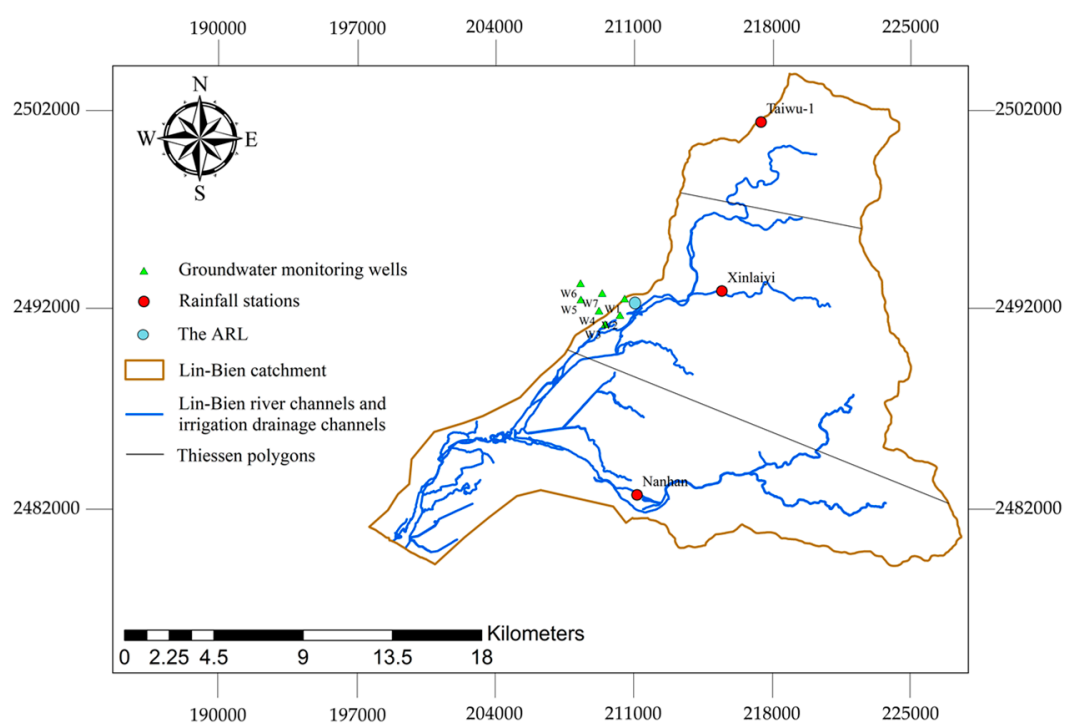

Figure 2. Location map of the study area (W1 to W7 is Well 1 to Well 7, respectively).

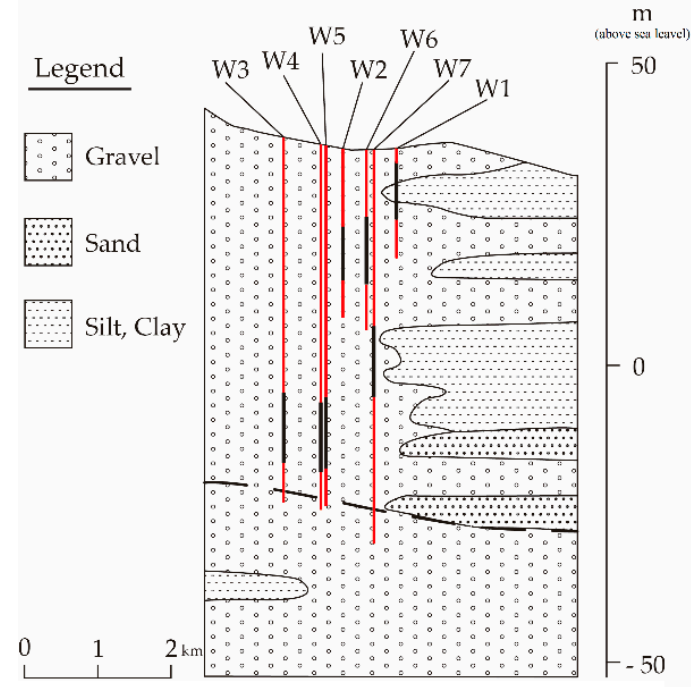

Figure 3. Hydrogeological profile of the study area (W1 to W7 is Well 1 to Well 7, respectively), after [25]. The A-A' profile of Figure 1.

The infiltration rate in this study area was evaluated by infiltration experiment in a $30 \times 30 \times$ $1.63 \mathrm{~m}$ test pit in 2002 [27]. The initial infiltration rate was about $22.76 \mathrm{~m} /$ day and the average infiltration rate was $17.26 \mathrm{~m} /$ day. After a serial infiltration test, the difference in infiltration rate between 2003 and 2005 had a maximum variation from 15.2 to $10.33 \mathrm{~m} /$ day due to the sand addition experiment [28]. If one compares the ARL infiltration result to other studies, the infiltration rate is about $5.9 \mathrm{~m} /$ day in the Rokugo Alluvial Fan, Northern Japan [29]; Liu et al.'s study on underground reservoirs in the western suburbs of Beijing estimates the infiltration rate between $1.0 \mathrm{~m} /$ day and $3.6 \mathrm{~m} /$ day [30]. 


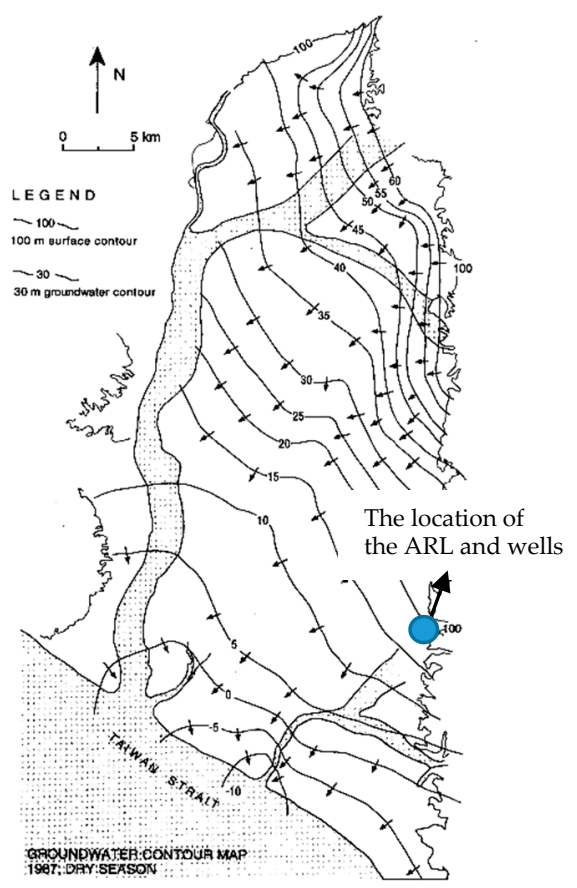

Figure 4. Groundwater piezometric map of the Pingtung Plain's dry season (November to May) [26].

\subsection{Data Collection and Process}

For this study, around five years of daily rainfall and daily groundwater table data collected from 2010/05 to 2015/12 were used. Before the model was established, original data underwent a pre-procedure process that included the following steps: (1) rainfall data processing, (2) groundwater table data processing, and (3) data normalization. The data collection and processing procedure steps are described in the following subsections.

\subsubsection{Rainfall Data}

Mean catchment rainfall can be calculated by several techniques, such as Thiessen polygon, isohyetal, polynomial, geostatistical, inverse distance weighted, multi-quadratic interpolation, and kriging [31,32]. This study referred to Tsou et al. [33] who used the Thiessen polygon method to calculate the mean catchment rainfall. The separated Thiessen's control area in the Taiwu-1 station was $50.76 \mathrm{~km}^{2}(15 \%)$, in the Xinlaiyi station it was $141.13 \mathrm{~km}^{2}(40 \%)$, and in the Nanhan station it was $156.97 \mathrm{~km}^{2}(45 \%)$. Based on research of the effects of rainfall, rainfall intensity, and groundwater table variation [34], the groundwater table is more sensitive in a five-day time-lag in a shallow layer [35]. Hence, this study combined the rainfall of past 1-day (R1) to past 5-day (R5) and rainfall intensity of past 1-day (RI1) to past 5-day (RI5) as the model inputs.

\subsubsection{Groundwater Data}

This study referred to Nayak et al. using 2-day groundwater differences as output for the model establishment [17]. In addition, considering the hydrogeology in a shallow groundwater aquifer, the groundwater variation is significantly affected by 10 days of rainfall [36]. Therefore, this study separated rainfall and groundwater data by events, where groundwater table rising past 10 days until groundwater drop was regarded as an event.

\subsubsection{Data Normalization}

To prevent an error associated with extreme values, data normalization was conducted for the data regarding rainfall, rainfall intensity, and groundwater differences. In addition, this procedure randomized the data using the concept of stochastic statistics to understand the relative change amount 
in the database. Therefore, the data employed were bounded between 0 and 1 using Equation (1) below, and then they were reverted by following Equation (2) [37]:

$$
\begin{gathered}
x_{\text {norm }}=\frac{x-x_{\min }}{x_{\max }-x_{\min }}, \\
x=x_{\text {norm }} \times\left(x_{\max }-x_{\min }\right)+x_{\min },
\end{gathered}
$$

where $x_{\text {norm }}$ is the normalized dimensionless variable, $x$ is the observed value of the variable, $x_{\min }$ is the minimum value of the variable, and $x_{\max }$ is the maximum value of the variable.

\subsection{Artificial Neural Network (ANN)}

An artificial neural network is an algorithm for processing information by its dynamic state response to inputs. The neural network computes its output at each iteration (epoch) and compares it with the expected output of each input (exemplary) vector in order to calculate the error. An ANN comprises parallel systems that are composed of processing elements (PEs) or neurons, which are assembled in layers and connected through several links or weights. After feeding input data to the input layer, they pass through and are operated on by the network until the output is produced at the output layer. Each neuron receives numerous inputs from other neurons through some weighted connections. These weighted inputs are then summed, and a standard threshold is added, generating the argument for a transfer function (usually linear, logistic, or hyperbolic tangent), which in turn produces the final output of the neuron $[38,39]$.

Hsieh et al. and Liao et al. compared MLP, a time lag recurrent network (TLRN), and a time delay neural network (TDNN) for groundwater simulation in the Lin-Bien River catchment. The MLP model is appropriate and suitable for this study area $[40,41]$. In order to learn more complex decision functions, inputs are fed into a number of perceptron nodes, each with its own set of weights and threshold [42]. The outputs of these nodes are then inputted into another layer of nodes, and so on. The output of the final layer of nodes is the output of the network. Such a network is termed MLP, and the layers of nodes whose input and output are seen only by other nodes are termed hidden [43]. The connection weights are computed by means of a learning algorithm. There are different variants of back-propagation learning algorithms in the literature [44]. The illustration of the MLP model is shown in Figure 5.

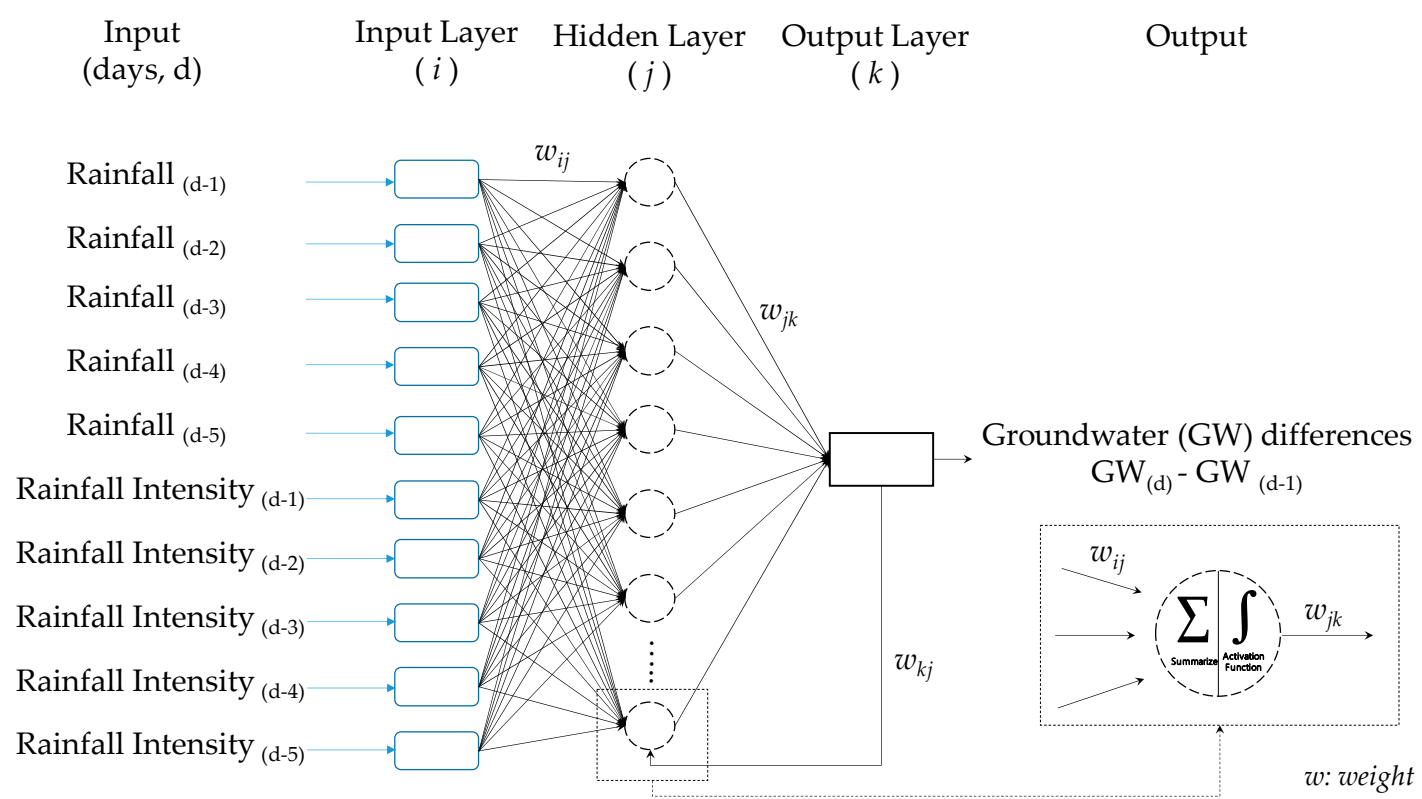

Figure 5. Illustration of the multilayer perception (MLP) model, after [39]. 


\subsection{Sensitivity Analysis (SA)}

A sensitivity analysis is a tool for model input importance assessment. Referring to Jha and Sahoo [20] and Memarian et al. [45,46], the SA calculation equation (Equation (3)) is given as follows [47]. When the change is small, the input is less sensitive in the model; on the contrary, when the changes are significant, the input is highly sensitive:

$$
S_{k}=\frac{\sum_{p=1}^{p} \sum_{n=1}^{n}\left(y_{i p}-\overline{y_{i p}}\right)}{a_{k}^{2}}
$$

where $S_{k}$ is the sensitivity index for input $k, \overline{y_{i p}}$ is the $i$ th output obtained with the fixed weights for the $p$ th pattern, $n$ is the number of network outputs, $p$ is the number of patterns, and $\alpha_{k}^{2}$ is the variance of the input $\mathrm{k}$.

\section{Results}

The ANN model was established using normalized rainfall and groundwater table data. The $\mathrm{R}^{2}$ was selected for model performance evaluation. Thus, the sensitivity analysis was conducted to evaluate the importance of the input for the model simulation. All results are discussed below.

\subsection{ANN Results}

Referring to the training, validation, and testing arrangements from Tayfur and Singh [48], Yang et al. [49] and Memarian et al. [45], respectively, this study used $70 \%$ of the data for training, 20\% for validation, and $10 \%$ for testing. With respect to the PE and hidden layer selection, Cheung et al. suggest 10 PEs in 1 hidden layer [50]. Thus, in this study, PEs were set at 10, and the hidden layer was set at 1 . The simulated results revealed that the $R^{2}$ of the MLP model in Well 1 was 0.848 , in Well 2 it was 0.854 , in Well 3 it was 0.914 , in Well 4 it was 0.897 , in Well 5 it was 0.759 , in Well 6 it was 0.841, and in Well 7 it was 0.812. All MLP model values showed high correlation $\left(R^{2}>0.8\right)$ except for Well 5, which was the farthest well from the Lin-Bien River and the ARL. Comparing Well 5 with a similar location well (Well 6), the well screen of Well 6 (13-25 m, above sea level) was shallower than that of Well 5 ( -17 to $5 \mathrm{~m}$, above sea level). The MLP model performance values $\left(\mathrm{R}^{2}\right)$ are shown in Table 3 . The model testing correlation relationship of each well is presented in Figures 6-12.

Table 3. MLP model performance.

\begin{tabular}{cc}
\hline Groundwater Monitoring Wells & $\mathbf{R}^{\mathbf{2}}$ \\
\hline Well 1 & 0.848 \\
Well 2 & 0.854 \\
Well 3 & 0.914 \\
Well 4 & 0.897 \\
Well 5 & 0.759 \\
Well 6 & 0.841 \\
Well 7 & 0.812 \\
\hline
\end{tabular}




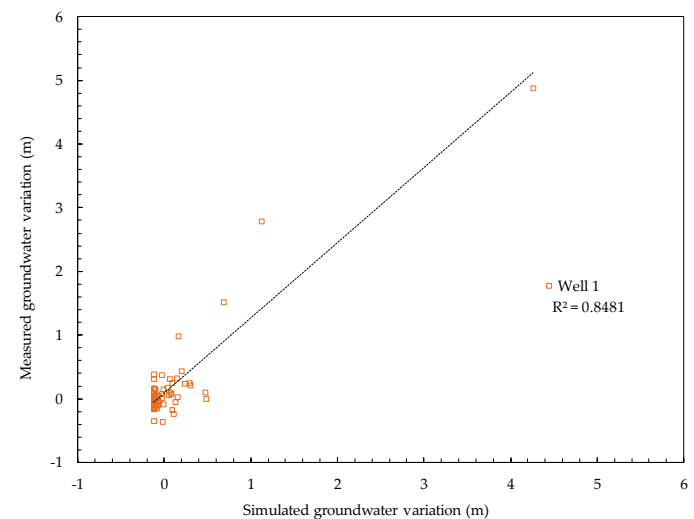

Figure 6. The model testing correlation relationship of Well 1.

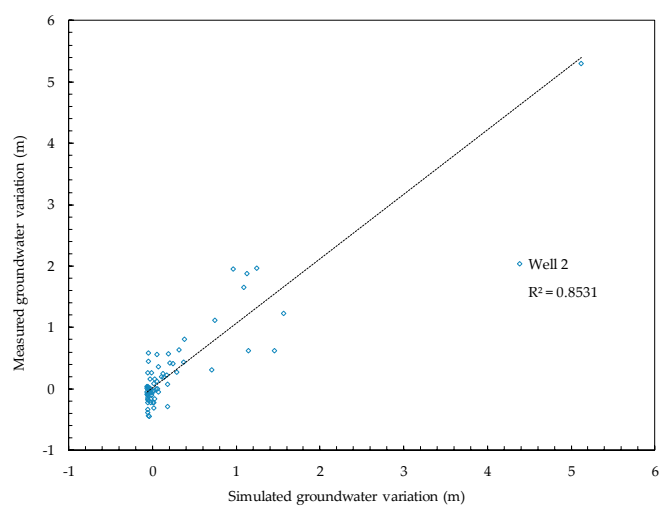

Figure 7. The model testing correlation relationship of Well 2.

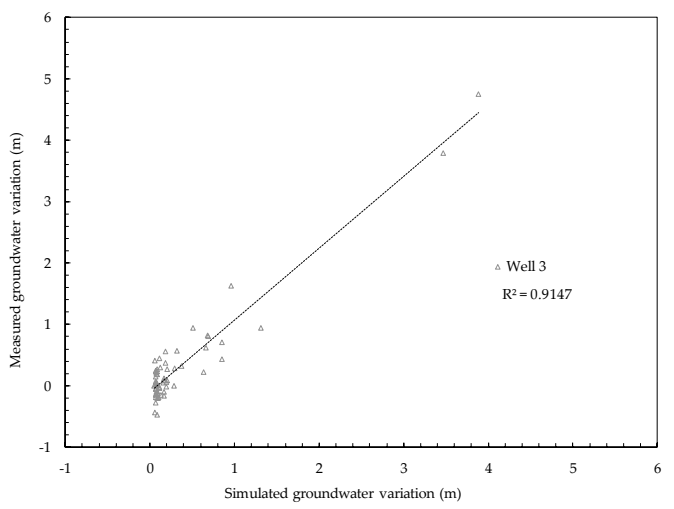

Figure 8. The model testing correlation relationship of Well 3.

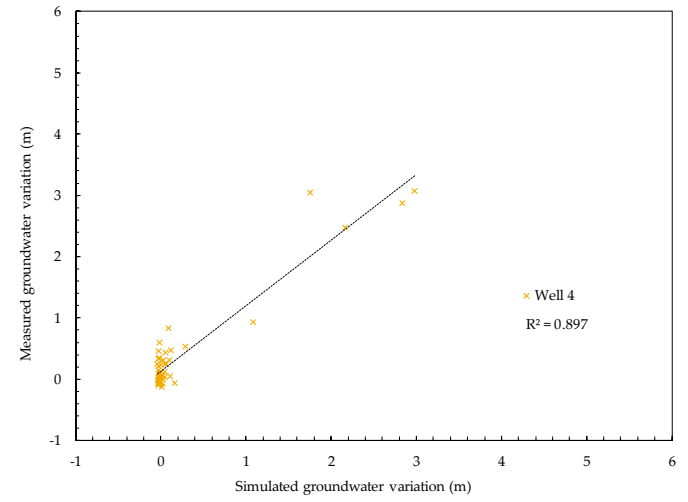

Figure 9. The model testing correlation relationship of Well 4. 


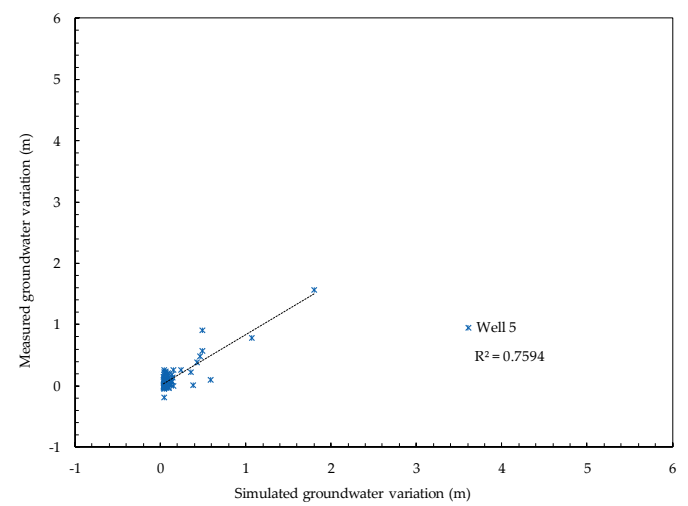

Figure 10. The model testing correlation relationship of Well 5.

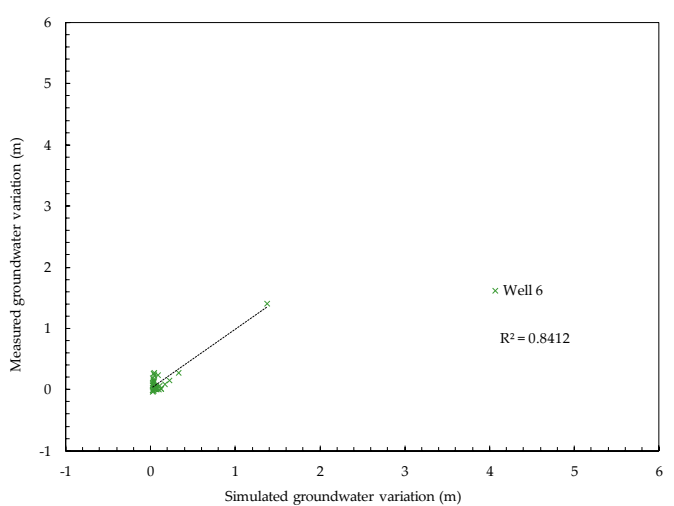

Figure 11. The model testing correlation relationship of Well 6.

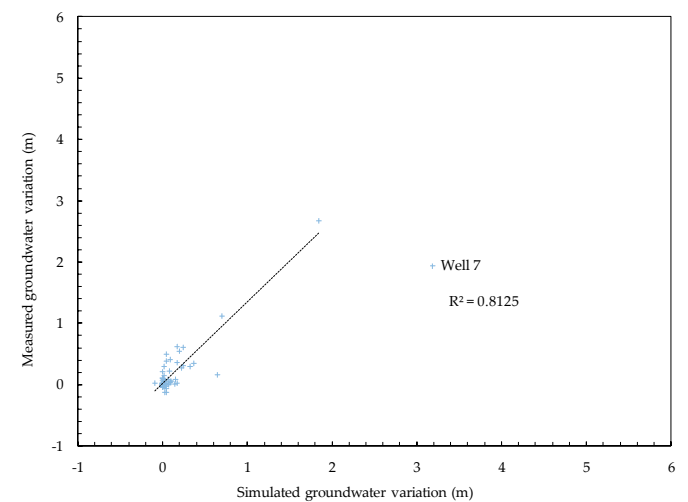

Figure 12. The model testing correlation relationship of Well 7.

\subsection{SA Results}

A sensitivity analysis was performed on the MLP model's simulation results to understand the relative sensitivity of each input to the output. All SA results are shown in Table 4 and Figure 13. Referring to Jha and Sahoo, the level of sensitivity was classified into five categories [20], as shown in Table 5. Based on the value of the sensitivity index for a particular input at the well, the influence level of the model's sensitivity to the input was ranked on a scale of 1 to 5 (Table 6). The sensitivity analysis indicated that, for past 5-day rainfall and rainfall intensity, R2 and RI3 were the highest and second highest sensitivities in Well 1; in Well 2, the results were R2 and R3; in Well 3, they were R4 and R2; in Well 4, they were RI2 and RI1; in Well 5, they were R5 and R4; in Well 6, they were RI4 and R2; and in Well 7, they were R4 and R5. The rainfall (R) is more sensitive than rainfall intensity (RI) in this research area. The highest and second highest sensitivities are listed in Table 7 (if the ranked result in the same value, the original SA index was compared). 
Table 4. Sensitivity analysis index.

\begin{tabular}{cccccccc}
\hline Inputs & Well 1 & Well 2 & Well 3 & Well 4 & Well 5 & Well 6 & Well 7 \\
\hline RI5 & 0.0216 & 0.0207 & 0.0163 & 0.0064 & 0.0096 & 0.0049 & 0.0145 \\
RI4 & 0.0045 & 0.0025 & 0.0035 & 0.0028 & 0.0047 & 0.0133 & 0.0033 \\
RI3 & 0.0223 & 0.0220 & 0.0156 & 0.0101 & 0.0076 & 0.0002 & 0.0164 \\
RI2 & 0.0040 & 0.0157 & 0.0231 & 0.0650 & 0.0044 & 0.0102 & 0.0037 \\
RI1 & 0.0017 & 0.0163 & 0.0130 & 0.0212 & 0.0051 & 0.0021 & 0.0200 \\
R5 & 0.0053 & 0.0132 & 0.0181 & 0.0035 & 0.0238 & 0.0084 & 0.0498 \\
R4 & 0.0203 & 0.0324 & 0.0639 & 0.0029 & 0.0181 & 0.0069 & 0.1489 \\
R3 & 0.0136 & 0.0594 & 0.0343 & 0.0036 & 0.0048 & 0.0036 & 0.0443 \\
R2 & 0.0849 & 0.1095 & 0.0362 & 0.0108 & 0.0030 & 0.0127 & 0.0092 \\
R1 & 0.0102 & 0.0027 & 0.0048 & 0.0173 & 0.0060 & 0.0042 & 0.0372 \\
\hline
\end{tabular}

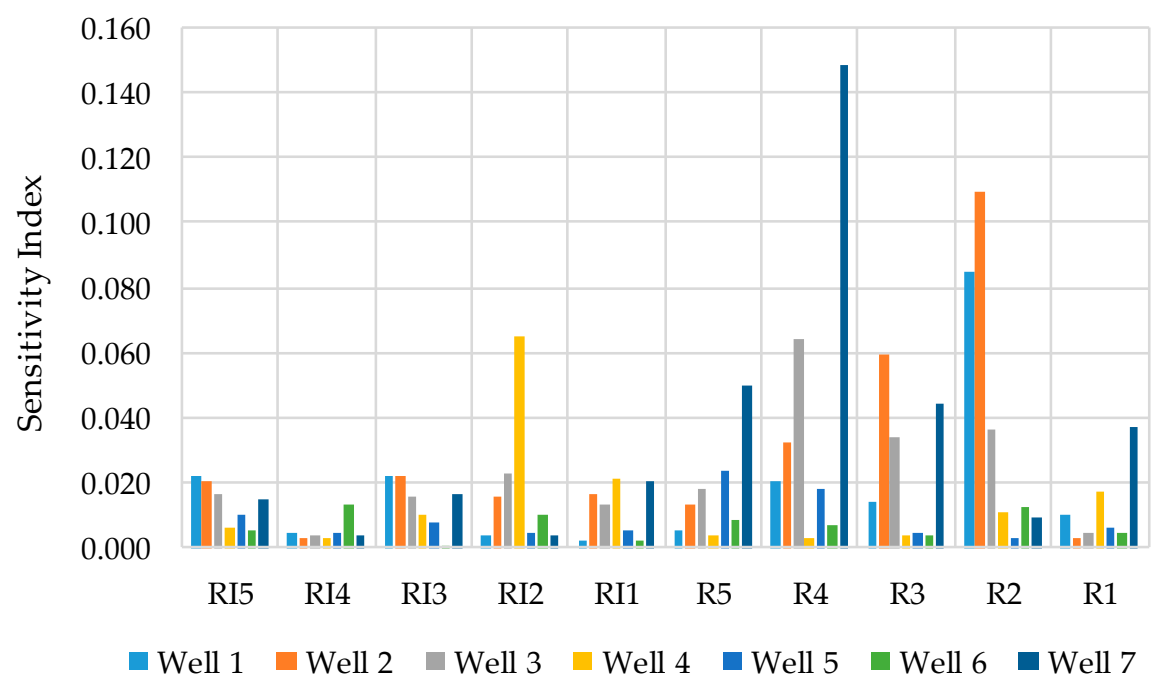

Figure 13. Sensitivity index of each input of the MLP model.

Table 5. Categorization of sensitivity and associated ranks.

\begin{tabular}{ccc}
\hline Category of Sensitivity & Value of Sensitivity Index & Rank \\
\hline 1. Very high sensitivity & $>0.1$ & 1 \\
2. High sensitivity & 0.05 to 0.1 & 2 \\
3. Moderate sensitivity & 0.01 to 0.05 & 3 \\
4. Low sensitivity & 0.005 to 0.01 & 4 \\
5. Very low sensitivity & $\leq 0.005$ & 5 \\
\hline
\end{tabular}

Table 6. Ranked sensitivity analysis index of each input.

\begin{tabular}{cccccccc}
\hline Inputs & Well 1 & Well 2 & Well 3 & Well 4 & Well 5 & Well 6 & Well 7 \\
\hline RI5 & 3 & 3 & 3 & 4 & 4 & 5 & 3 \\
RI4 & 5 & 5 & 5 & 5 & 5 & 3 & 5 \\
RI3 & 3 & 3 & 3 & 3 & 4 & 5 & 3 \\
RI2 & 5 & 3 & 3 & 2 & 5 & 3 & 5 \\
RI1 & 5 & 3 & 3 & 3 & 4 & 5 & 3 \\
R5 & 4 & 3 & 3 & 5 & 3 & 4 & 3 \\
R4 & 3 & 3 & 2 & 5 & 3 & 4 & 1 \\
R3 & 3 & 2 & 3 & 5 & 5 & 5 & 3 \\
R2 & 2 & 1 & 3 & 3 & 5 & 3 & 4 \\
R1 & 3 & 5 & 5 & 3 & 4 & 5 & 3 \\
\hline
\end{tabular}


Table 7. Highest and 2nd highest sensitivities.

\begin{tabular}{ccccc}
\hline Groundwater & \multicolumn{2}{c}{ Highest Sensitivity } & \multicolumn{2}{c}{ 2nd Highest Sensitivity } \\
\cline { 2 - 5 } Monitoring Wells & Index & Variable & Index & Variable \\
\hline Well 1 & 2 & R2 & 3 & RI3 \\
Well 2 & 1 & R2 & 2 & R3 \\
Well 3 & 2 & R4 & 3 & R2 \\
Well 4 & 2 & RI2 & 3 & RI1 \\
Well 5 & 3 & R5 & 3 & R4 \\
Well 6 & 3 & RI4 & 3 & R2 \\
Well 7 & 1 & R4 & 3 & R5 \\
\hline
\end{tabular}

When considering the SA results and the information in the location map of the study area (Figure 2), one can see that Wells 1 to 3 are within the study catchment, which is adjacent to Lin-Bien River and the ARL, and responded faster in R1, R2, R3, RI1, RI2, RI3, respectively; Wells 4 to 7 are outside the catchment and far from the ARL; R4, R5, RI4, RI5 were found to be sensitive in Wells 5 to 7 . It can be concluded that the groundwater table variation adjacent to the Lin-Bien River and the ARL is response-related with rainfall time-lag. It is worth noting that, although Well 4 is located outside the catchment, it still has a certain degree of sensitivity from past 3-day rainfall (R1, R2, R3, RI1, RI2, RI3, respectively), the reason for which is discussed below.

The sensitivity of each well is influenced by the well screen position. The reason for past 3-day rainfall (R1, R2, R3, RI1, RI2, RI3, respectively) being sensitive in Well 4 is that the well screen's location is similar to the one in Well 3. After considering the SA results about the information for each groundwater monitoring well (Table 2), it was observed that 2-day rainfall (R1, R2, RI1, RI2, respectively) was more sensitive due to the well screen location being above sea level, for example, in Wells 1, 2, and 6.

\section{Discussion}

The purpose of this study was to discover the highly sensitive variables of a groundwater simulation model adjacent to an ARL using short-term rainfall. The model was established by MLP with past 10-day short-term events. Normalized rainfall (R1 to R5), rainfall intensity (RI1 to RI5), and groundwater data were selected as model variables. The $\mathrm{R}^{2}$ was used for model accuracy assessment [18]. A sensitivity analysis (SA) was conducted to evaluate the importance of each model input. The study results are discussed as follows.

First, during the model establishment, the MLP model was suggested for development $[5,40,41]$. The best fit $\mathrm{R}^{2}$ of the MLP model was 0.914 (Well 3) and the lowest $\mathrm{R}^{2}$ in MLP was 0.759 (Well 5). This model uses rainfall as an input; the rainfall converges in the ARL and the river then infiltrates into the groundwater layer. The farthest well (Well 5) from the Lin-Bien River and the ARL responded more slowly than the other wells with a lower $\mathrm{R}^{2}$. Comparing Well 5 with a similar location well (Well 6), the well screen of Well 6 (13-25 m, above sea level) was shallower than that of Well 5 ( -17 to $5 \mathrm{~m}$, above sea level). Therefore, the rainfall response in Well 6 was faster than in Well 5.

Second, a sensitivity analysis was conducted for input importance evaluation. The highest and second highest inputs in Well 1 were R2 and RI3; in Well 2, they were R2 and R3; in Well 3, they were R4 and R2; in Well 4, they were RI2 and RI1; in Well 5, they were R5 and R4; in Well 6, they were RI4 and R2; and in Well 7, they were R4 and R5. The rainfall amount (R) was more sensitive than rainfall intensity (RI) in this research area.

Finally, when considering the SA results for the Lin-Bien River catchment area (Figure 2) and the relevant hydrogeological profile (Figure 3), a slight difference between "within the catchment" and "outside the catchment" can be found. Wells 1 to 3 are in the study catchment and adjacent to Lin-Bien River and the ARL, and responded faster in past 3-day rainfall (R1, R2, R3, RI1, RI2, RI3, respectively) than the other four wells. On the other hand, R4, R5, RI4, RI5 were found to be sensitive in Wells 5 to 7 . 
Although Well 4 was located outside the catchment, it still had a certain degree of sensitivity from past 3-day rainfall (R1, R2, R3, RI1, RI2, RI3, respectively) because the location of its well screen was similar to the one in Well 3. Moreover, R2 was highly sensitive due to the well screen being located above sea level, that is, Wells 1,2, and 6 . It can be concluded that the groundwater table variation in this study area is response-related with the distance from the wells to the river and the ARL, and the rainfall time-lag.

\section{Conclusions}

A sensitivity analysis is not only a tool for the input importance evaluation of a groundwater simulation model, but it is also a useful method, considered with a hydrogeological map and geological characteristics, for explaining influences on the physical mechanism of groundwater infiltration, taking into account the complexity of the relevant physical groundwater model's development. This SA study is helpful to researchers wishing to study related ARL efficiency issues.

Author Contributions: The authors contributed equally in preparing this manuscript. They are all well conversant with its content and have agreed to the sequence of the authorship. S.-H.H. initiated and provided the concept and monitored the groundwater table variation. L.-W.L. conducted the data analysis. W.-G.C. reviewed and edited the manuscript. Y.-M.W. supervised the analyzing work, and provided oversight for the analysis of data and editing of the manuscript.

Funding: This research was funded by the Pingtung County Government, Taiwan, under the grant of "2015 Hydrological Data Analysis and Evaluation of the Great Chaozhou Artificial Groundwater Recharge Lake Implementation Plan" and partially funded by MOST, Taiwan, grant number 105-2221-E-020-009.

Acknowledgments: The authors gratefully acknowledge the team of Hydraulic Laboratory of NPUST for the field observation and data analysis. Also to acknowledge the contact person Wei-Tai Lee for his sincere help.

Conflicts of Interest: The authors declare no conflict of interest.

\section{References}

1. Peng, T.R.; Lu, W.C.; Chen, K.Y.; Zhan, W.J.; Liu, T.K. Groundwater-recharge connectivity between a hills-and-plains' area of western Taiwan using water isotopes and electrical conductivity. J. Hydrol. 2014, 517, 226-235. [CrossRef]

2. Wang, C.H.; Kuo, C.H.; Chang, F.C. The Changing Face of the Groundwater Environment in Taiwan. Bull. Cent. Geol. Surv. 2004, 17, 1-22.

3. T.W.R.A. Taiwan Water Usage Annual Report; Taiwan Water Resources Agency, Ministry of Economic Affairs: Taipei, Taiwan, 2017; p. A-14.

4. T.W.R.A. Taiwan Groundwater Withdrawal and Pumping. Available online: https://www.wra.gov.tw/6950/ 7170/7356/7488/13319 (accessed on 14 July 2019).

5. Liao, F.L. Using Artificial Neural Network for Estimating the Effects on Groundwater from Artificial Recharge or Rainfall. National Pingtung University of Science and Technology: Pingtung County, Taiwan, 2017.

6. T.P.W.C.B. Compilation and Analysis of Existing Groundwater and Subsidence Data of Taiwan II-the Pingtung Plain; Ministry of Economic Affairs: Taipei, Taiwan, 1994.

7. T.P.W.C.B. Study on the Improvement of the Groundwater Monitoring System in the Pingtung Plain; Ministry of Economic Affairs: Taipei, Taiwan, 1998.

8. Ineson, J. Hydrogeological and Groundwater Aspects of Artificial Recharge. In Proceedings of the Artificial Groundwater Recharge Conference, England, UK, 21-24 September 1970; pp. 1-14.

9. Muckel, D. Artificial Recharge in Relation to Groundwater Storage. In Proceedings of the Annual Conference on Water for Texas, College Station, TX, USA, 16-18 September 1958; pp. 85-94.

10. Walton, W.C. Groundwater Resource Evaluation. In McGraw-Hill Series in Water Resources and Environmental Engineering (USA) eng; McGraw-Hill: New York, NY, USA, 1970.

11. Morbidelli, R.; Saltalippi, C.; Flammini, A.; Cifrodelli, M.; Picciafuoco, T.; Corradini, C.; Govindaraju, R. Laboratory investigation on the role of slope on infiltration over grassy soils. J. Hydrol. 2016, 543, 542-547. [CrossRef] 
12. Morbidelli, R.; Corradini, C.; Saltalippi, C.; Flammini, A.; Dari, J.; Govindaraju, R. A New Conceptual Model for Slope-Infiltration. Water 2019, 11, 678. [CrossRef]

13. Chen, C.T.; Chen, L.S.; Huang, J.Y.; Huang, S.J. A Study on Ground Water Level Forecasting by Combining Neural Networks and Semi-variogram Model. J. Taiwan Agric. Eng. 2015, 61, 14-28. [CrossRef]

14. Coppola, E.A., Jr.; Rana, A.J.; Poulton, M.M.; Szidarovszky, F.; Uhl, V.W. A neural network model for predicting aquifer water level elevations. Groundwater 2005, 43, 231-241. [CrossRef] [PubMed]

15. Yu, H.-L.; Lin, Y.-C. Analysis of space-time non-stationary patterns of rainfall-groundwater interactions by integrating empirical orthogonal function and cross wavelet transform methods. J.Hydrol. 2015, 525, 585-597. [CrossRef]

16. Daliakopoulos, I.N.; Coulibaly, P.; Tsanis, I.K. Groundwater level forecasting using artificial neural networks. J. Hydrol. 2005, 309, 229-240. [CrossRef]

17. Nayak, P.C.; Rao, Y.S.; Sudheer, K. Groundwater level forecasting in a shallow aquifer using artificial neural network approach. Water Resour. Manag. 2006, 20, 77-90. [CrossRef]

18. Sahoo, S.; Jha, M.K. Groundwater-level prediction using multiple linear regression and artificial neural network techniques: A comparative assessment. Hydrogeol. J. 2013, 21, 1865-1887. [CrossRef]

19. Liu, L.W.; Hsieh, S.H.; Chung, W.G.; Wang, Y.M. Sensitivity Analysis on the Rising Relation of Short-term Rainfall and Unconfined Aquifer Groundwater Table. In Proceedings of the 2017 th International Conference on Coastal and Ocean Engineering (ICCOE 2017), Osaka, Japan, 29 March 2017; p. 64.

20. Jha, M.K.; Sahoo, S. Efficacy of neural network and genetic algorithm techniques in simulating spatio-temporal fluctuations of groundwater. Hydrol. Process. 2015, 29, 671-691. [CrossRef]

21. Ahlawat, R. Hydrological Data Network Modelling Using Artificial Neural Network in Betwa Catchment. Int. J. Soft Comput. Eng. (IJSCE) 2014, 3, 132-134.

22. Ting, C.S.; Kerh, T.; Liao, C.J. Estimation of groundwater recharge using the chloride mass-balance method, Pingtung Plain, Taiwan. Hydrogeol. J. 1998, 6, 282-292. [CrossRef]

23. Ting, C.S.; Zhou, Y.; Vries, J.D.; Simmers, I. Development of a Preliminary Ground Water Flow Model for Water Resources Management in the Pingtung Plain, Taiwan. Groundwater 1998, 36, 20-36. [CrossRef]

24. T.P.W.C.B. Investigation Report on Ground Water Resources of the Pingtung Plain; Ministry of Economic Affairs: Taichung, Taiwan, 1961.

25. Ministry of Economic Affairs. Geological Sensitive Groundwater Recharge Area Delineation Plan-G0002 Pingtung Plain; Ministry of Economic Affairs: Taipei, Taiwan, 2014.

26. Ting, C.S. Groundwater Resources Evaluation and Management for Pingtung Plain, Taiwan. Ph.D. Thesis, Vrije Universiteit, Amsterdam, The Netherlands, 1997.

27. C.T.C.I. Pingtung County Water Resources Development and Conservation of The Overall Planning and Lin-Bien River Upstream Artificial Lake Engineering Project Settings-Groundwater Recharge Field Test Report; Pingtung County Government: Pingtung, Taiwan, 2000; pp. 3-23.

28. Tu, Y.-C.; Ting, C.-S.; Tsai, H.-T.; Chen, J.-W.; Lee, C.-H. Dynamic analysis of the infiltration rate of artificial recharge of groundwater: A case study of Wanglong Lake, Pingtung, Taiwan. Environ. Earth Sci. 2011, 63, 77-85. [CrossRef]

29. Hida, N.; Ishikawa, E.; Ohta, Y. Experimental Study of Basin Artificial Recharge of Ground Water in Rokugo Alluvial Fan, Northern Japan. J. Groundw. Hydrol. 1999, 41, 23-33. [CrossRef]

30. Liu, J.X.; Cai, Q.S. Research on the Groundwater Reservoir in the West Suburb of Beijing; Geological Publishing Company: Beijing, China, 1988.

31. Abo-Monasar, A.; Al-Zahrani, M.A. Estimation of rainfall distribution for the southwestern region of Saudi Arabia. Hydrol. Sci. J. 2014, 59, 420-431. [CrossRef]

32. Ewea, H.A.; Elfeki, A.M.M.; Bahrawi, J.A.; Al-Amri, N.S. Sensitivity analysis of runoff hydrographs due to temporal rainfall patterns in Makkah Al-Mukkramah region, Saudi Arabia. Arab. J. Geosci. 2016, 9, 424. [CrossRef]

33. Tsou, I.; Chen, C.N.; Wang, Y.M.; Kuo, Y.C. A Simulation Study for Flood Disaster Reduction by Detention Pond in Lin-Bian River Basin. In Proceedings of the International Conference on Disaster Management, Kumamoto, Japan, 25 August 2012; pp. 399-406.

34. Bogaard, T.A. Analysis of Hydrological Processes in Unstable Clayey Slopes. Ph.D. Thesis, Utrecht University, Utrecht, The Netherlands, 2001. 
35. Jasmin, I.; Murali, T.; Mallikarjuna, P. Statistical analysis of groundwater table depths in upper Swarnamukhi River basin. J. Water Resour. Prot. 2010, 2, 577. [CrossRef]

36. Apps, J.A.; Zheng, L.; Spycher, N.; Birkholzer, J.T.; Kharaka, Y.; Thordsen, J.; Kakouros, E.; Trautz, R. Transient changes in shallow groundwater chemistry during the MSU ZERT $\mathrm{CO}_{2}$ injection experiment. Energy Procedia 2011, 4, 3231-3238. [CrossRef]

37. Wang, Y.-M.; Elhag, T.M. An adaptive neuro-fuzzy inference system for bridge risk assessment. Expert Syst. Appl. 2008, 34, 3099-3106. [CrossRef]

38. Talebizadeh, M.; Morid, S.; Ayyoubzadeh, S.A.; Ghasemzadeh, M. Uncertainty analysis in sediment load modeling using ANN and SWAT model. Water Resour. Manag. 2010, 24, 1747-1761. [CrossRef]

39. Traore, S.; Wang, Y.M.; Chung, W.G. Predictive accuracy of backpropagation neural network methodology in evapotranspiration forecasting in Dédougou region, western Burkina Faso. J. Earth Syst. Sci. 2014, 123, 307-318. [CrossRef]

40. Hsieh, S.H.; Chung, W.G.; Wang, Y.M. Using Artificial Neural Networks for Groundwater Table in Unconfined Aquifer Forecasting. In Proceedings of the 2017 4th International Conference on Coastal and Ocean Engineering (ICCOE 2017), Osaka, Japan, 29 March 2017; p. 63.

41. Liao, F.L.; Liu, L.W.; Chung, W.G.; Wang, Y.M. Using ANN for modeling the unconfined groundwater table variation induced by artificial recharge lake in dry season. In Proceedings of the 2017 4th International Conference on Coastal and Ocean Engineering (ICCOE 2017), Osaka, Japan, 29 March 2017; p. 98.

42. Bishop, C.M. Neural Networks for Pattern Recognition; Oxford University Press: New York, NY, USA, 1995.

43. Lippmann, R.P. An introduction to computing with neural nets. IEEE Assp Mag. 1987, 4, 4-22. [CrossRef]

44. Hagan, M.T.; Demuth, H.B.; Beale, M.H.; De Jesús, O. Neural Network Design; Pws Pub.: Boston, MA, USA, 1996; Volume 20.

45. Memarian, H.; Balasundram, S.K.; Tajbakhsh, M. An expert integrative approach for sediment load simulation in a tropical watershed. J. Integr. Environ. Sci. 2013, 10, 161-178. [CrossRef]

46. Memarian, H.; Bilondi, M.P.; Rezaei, M. Drought prediction using co-active neuro-fuzzy inference system, validation, and uncertainty analysis (case study: Birjand, Iran). Theor. Appl. Climatol. 2016, 125, 541-554. [CrossRef]

47. Principe, J.C.; Euliano, N.R.; Lefebvre, W.C. Neural and Adaptive Systems: Fundamentals through Simulations; Wiley: New York, NY, USA, 2000; Volume 672.

48. Tayfur, G.; Singh, V.P. ANN and fuzzy logic models for simulating event-based rainfall-runoff. J. Hydraul. Eng. 2006, 132, 1321-1330. [CrossRef]

49. Yang, C.T.; Marsooli, R.; Aalami, M.T. Evaluation of total load sediment transport formulas using ANN. Int. J. Sediment Res. 2009, 24, 274-286. [CrossRef]

50. Cheung, S.O.; Wong, P.S.P.; Fung, A.S.; Coffey, W. Predicting project performance through neural networks. Int. J. Proj. Manag. 2006, 24, 207-215. [CrossRef]

(C) 2019 by the authors. Licensee MDPI, Basel, Switzerland. This article is an open access article distributed under the terms and conditions of the Creative Commons Attribution (CC BY) license (http://creativecommons.org/licenses/by/4.0/). 